\title{
Enhancing the Social and Natural Capital of Canadian Agro-Ecosystems through Incentive-Based "Alternative Land Use Services" (ALUS) Programs: Recurring Themes and Emerging Lessons
}

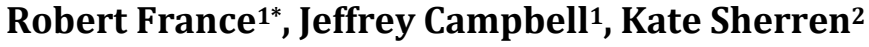 \\ ${ }^{1}$ Rural Research Centre, Faculty of Agriculture, Dalhousie University, Halifax, Canada \\ ${ }^{2}$ School for Resource and Environmental Studies, Dalhousie University, Halifax, Canada \\ Email: ${ }^{\star}$ france@dal.ca
}

How to cite this paper: France, R., Campbell, J., \& Sherren, K. (2019). Enhancing the Social and Natural Capital of Canadian Agro-Ecosystems through Incentive-Based "Alternative Land Use Services" (ALUS) Programs: Recurring Themes and Emerging Lessons. Journal of Geoscience and Environment Protection, 7, 139-162. https://doi.org/10.4236/gep.2019.712010

Received: August 20, 2019

Accepted: December 20, 2019

Published: December 23, 2019

Copyright $\odot 2019$ by author(s) and Scientific Research Publishing Inc. This work is licensed under the Creative Commons Attribution International License (CC BY 4.0).

http://creativecommons.org/licenses/by/4.0/

\begin{abstract}
Alternative Land Use Services (ALUS) is an incentive-based program established in Canada to pay farmers for their voluntary delivery of ecosystem services (ES). All seven ALUS programs across the country were examined using a standardized case-study approach based on site visits, reading internal documents, attending program meetings, and engaging in semi-structured interviews with program administrators, participating farmers, and advisory board members. Direct content analysis was used to highlight recurrent themes and emerging lessons in relation to the salient particulars of program physical location, administration framework, delivery of ES, and development and receipt by communities. Our three major findings are: 1) Overall, ALUS has been judged by participants to be a very successful program, whose strength is that it is completely voluntary, non-permanent, and readily adaptable to each location's environmental conditions, economic funding base, and cultural milieu. 2) One serious shortcoming of all ALUS programs is a general lack of quantifiable data on their ability to increase ES. Instead, environmental benefits are either assumed or based on the idea that the areal extent of enrolled land is the sole measure of its environmental worth. 3) It may be that the social impact of ALUS is its greatest success. In this regard, for farmers, it is the process of engaging in land-use decision making and the recognition of their role as environmental stewards that is a bigger motivation for participating in an ALUS program than the modest financial incentives which they receive.
\end{abstract}




\section{Keywords}

Agro-Ecosystem Services, Incentive Payments, Grassroots Participation, Natural and Social Capital

\section{Introduction}

Innovative land-use planning is increasingly being employed in variable forms around the world as a means of enhanced habitat management in order to ensure sustainable agricultural policy. Since 2008, across Canada, one such mechanism, “Alternative Land Use Services" (ALUS), has been developed in different ecological and sociopolitical environments and governance-management frameworks in five Canadian provinces (Figure 1) to deliver ecosystem services (ES) from privately held agricultural landscapes (France \& Campbell, 2015). ALUS operates on six core principles (Table 1), and is a grassroots initiative based on payments for both land-sharing and land-sparing approaches (sensu Fischer et al., 2008; Grau et al., 2013) matching local agriculture and conservation needs. Best management practices (BMPs) include: tree planting in legislated riparian buffer zones, setting aside wetlands and grassed headland reserves, expanding existing buffer zones, installing soil conservation structures, implementing practices to reduce soil erosion such as retiring high slope land, and constructing livestock exclusion fencing along waterways (see photographs in France \& Campbell, 2015). The purpose of the present study was to undertake the first, cross-system examination of all the Canadian ALUS programs, and to highlight, in this special publication forum on "land use planning, management and sustainability" for an international readership, the recurring themes and lessons that have emerged.

Table 1. Core principles of ALUS programs (Bailey \& Reid, 2004; KAP, 2004; ALUS, 2011).

- Participation in the ALUS program is completely voluntary.

- The amount of land enrolled in ALUS is capped at a maximum (usually about 20 percent) in order to maintain an agriculturally based landscape.

- ALUS is designed to be integrated into existing land-use policies, conservation initiatives, and incentive programs so as to compliment them rather than compete against them.

- Lands that are deemed of marginal productivity or of noted environmental fragility are the primary target of the ALUS program, with the intention being to retire or alter cultivation practices for ecological benefits.

- In addition to being voluntary, ALUS is meant to be flexible with short-term contracts. Farmers are also permitted to withdraw from the program earlier than the contract-specified duration, but will have to reimburse any payments received.

- To comply with trade obligations, ALUS programs must be "production neutral", meaning the program must be compliant with World Trade Organization green box policies. These green box policies allow payment for conservation and environmental projects, as well as research, crop insurance, extension work, and other policies associated with agriculture that do not distort production or provide price support for agricultural producers. 
Although the ALUS concept has expanded across Canada, published scholarship on the programs, especially of a comparative basis, is lacking. An early scoping survey we conducted in 2012 through bibliographic and on-line research showed that whereas ALUS was well documented in the popular media (116 press releases), there had not been any publications in the international literature. In comparison, more than a hundred publications exist on the older Conservation Reserve Program (CRP) in the United States (Riley, 2010), and other similarly themed programs around the world, including Canada's Environmental Farm Plans (EFPs) (Robinson, 2006). The preliminary research undertaken on ALUS is largely available only in internal and grey literature documents that have not been widely circulated. More recent scholarship about ALUS is restricted to particulars about individual programs underway in Norfolk County (Mackenzie, 2008; Rosenberg, 2010; MacLean, 2014; Irvine, 2013) and elsewhere in Ontario (Ouelett, 2018), the Rural Municipality of Blanshard, Manitoba (RMB) (Mann et al., 2014; Holland, 2015), and the province of Prince Edward Island (PEI) (Johnston, 2012; Lantz et al., 2012; Kolinjivadi et al., 2019). Only two of these ten site-specific studies have been published in the peer-reviewed literature. And no cross-system examination has been published beyond background descriptions of the developmental case-histories of each of the independent ALUS programs across Canada (France \& Campbell, 2015).

Our intent herein is to trade the detailed specifics of individual case-study analyses, such as those noted above, with a broad overview garnered through a cross-system, largely qualitative, examination, and the first undertaken, of the entire corpus of Canadian ALUS programs. The purpose of the present study, therefore, is based on the belief that by taking such a synoptic approach, we can highlight the recurring themes and emerging lessons with respect to how ALUS operates and is perceived. This approach was motivated by the study goal of identifying the need for future improvements in design and implementation as well as more-detailed research that should be undertaken if this particular strategy is to continue or to be expanded, as is being considered. Furthermore, despite the present paper pertaining solely to this particular Canadian program of payment for agro-ecosystem services, we believe that this example of sustainable land-use policy and planning will be of interest to an international readership involved in developing similar programs within their own respective countries.

\section{Methods}

As detailed in France and Campbell (2015) and indicated in Figure 1, there are two active ALUS programs in Ontario (Norfolk, Grey/Bruce) and two in Alberta (Vermillion River, Parkland) that are operated at a county level. In Saskatchewan, there is one ALUS program, involving four rural municipalities (South Qu'Appelle, Indian Head, Lajord, Francis). Prince Edward Island (PEI) is the only province to have implemented ALUS as a province-wide policy. Manitoba, which was the location of the first pilot project (Blanshard), no longer has an 


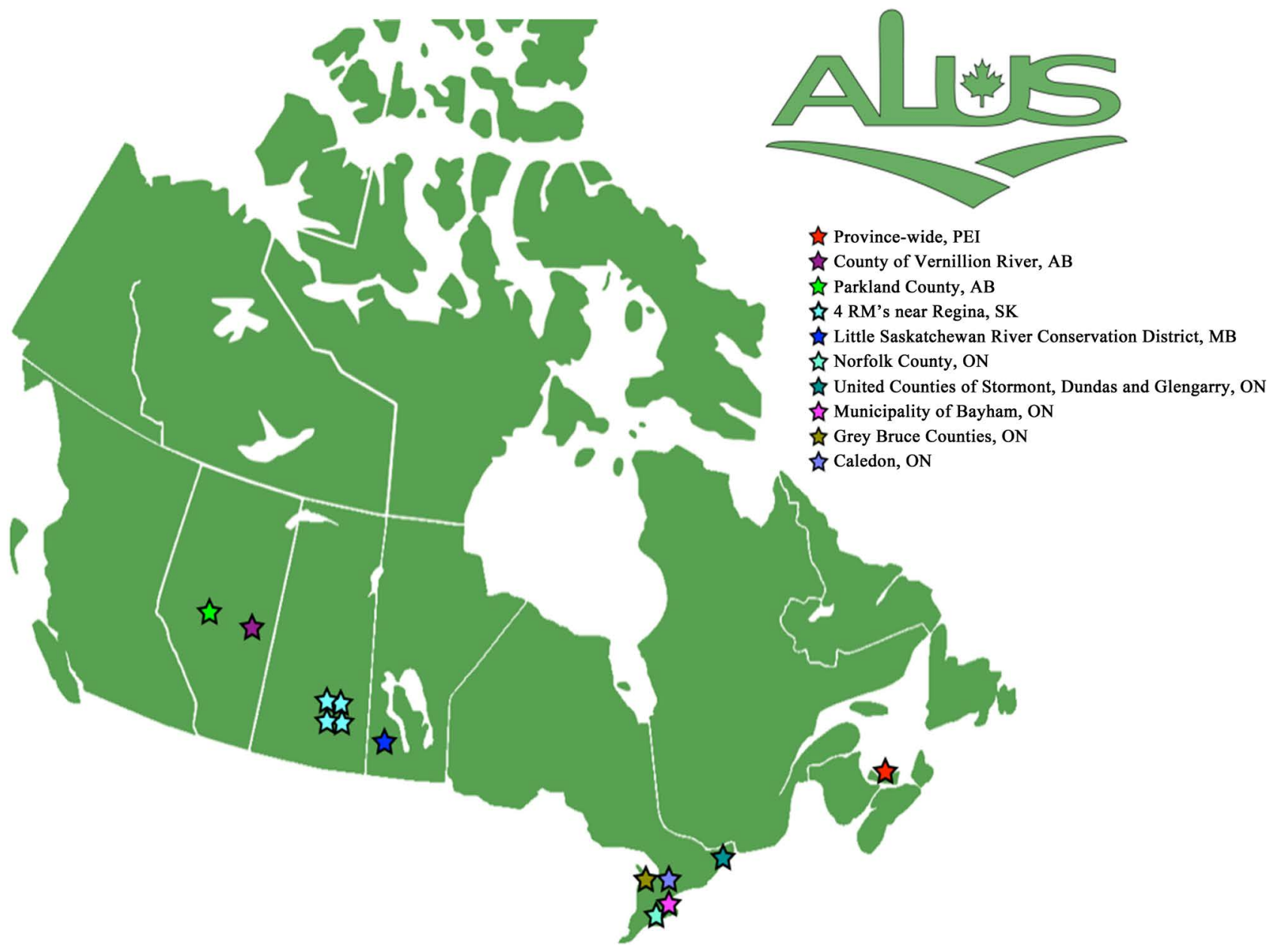

Figure 1. ALUS programs discussed in the text. From left (west) to right (east), Alberta: the two counties of Vermillion River and Parkland; Saskatchewan: four rural municipalities (RMs) near Regina; Manitoba: the Little Saskatchewan River District in the Rural Municipality of Blanshard; Ontario: the two counties of Norfolk and Grey/Bruce (plus additional proposed programs not elaborated on in the text); and the province-wide program in Prince Edward Island (PEI). Detailed, site-specific maps are shown in Campbell (2014).

operating ALUS program though there is interest from both farmers and conservation groups in restarting the program there in the future.

To meet the objective of investigating the ALUS programs, each location was examined using a standardized case-study approach to provide a comprehensive cross-system comparison. Descriptive case-histories were constructed based on site visits, existing grey literature documents, internal documents from ALUS program meetings, and in-depth, semi-structured interviews with program administrators and participating farmers. Details about the visits, physical and socio-demographic particulars, agro-environmental backgrounds, and diachronic developmental descriptions for all the study sites are presented in France and Campbell (2015).

For the present interpretation of cross-system recurring themes and emerging lessons, meetings and unstructured interviews with program coordinators were recorded at the time of visits in conjunction with compiling written field notes. 
Anecdotal conversations, which were not formally recorded, took place with farmers who are currently or once were involved with the ALUS programs. Activities engaged in during site visits included one-on-one meetings with program coordinators; attending group Partnership Advisory Committee (PAC) meetings; tours of retired marginal farmland, created wetlands and pollinator strips, and planted shelterbelts and native prairies with farmers and program administrators; and direct participation in riparian tree planting, wetland construction, and alternative water access projects, as well as surveying potential sites for future BMP implementation with participants. During formal interviews with administrators and PAC members, and anecdotal conversations with farmers, questions about the perceived strengths, benefits, weaknesses, and suggested areas for improvement of ALUS were answered honestly and without bias. The qualitative nature of such interviews and conversations enables collection of information about values and attitudes that are frequently missed by quantitative surveys. As detailed by Greenland-Smith (2014), unstructured interviews in the form of conversations with open-ended and flexible question prompts (Zhang \& Wildemuth, 2009) are deemed most valuable to the study of agricultural ES. Such conversational acquisition of data enables researchers to obtain a wider range of attitudinal responses than through answers to set questions in surveys (Kvale \& Brinkmann, 2009). In unstructured interviews, questions are generated spontaneously, though not without meticulous prior preparation of targeted avenues of investigation, as was done in this case. The opinions of 8 program administrators (including top-level coordinators), 19 participating farmers, and 12 other PAC members were obtained in this way. The bulk of interviewees (63\% for administrators, $75 \%$ for PAC members, and $79 \%$ for farmers) were all middle-aged (40 to 65 ), with most being male (75\% for administrators, $83 \%$ for PAC members, and $100 \%$ for farmers). The organizations of the various PAC members, such as eNGOs, are listed in France \& Campbell (2015).

The main focus of the research was on investigating farmer uptake, and the administration and development of ALUS. Program funding, although the advantages and disadvantages of their sources are briefly touched upon, was not the focus of the research. Nor do we do not attempt to rationalize why ALUS should be funded or how funding should be allocated within individual programs.

Site visits to all ALUS programs were a critical research component for this project. Such in situ investigations are necessary in the landscape architecture case-study methodology of Francis (1999), which was modified to focus on the following germane aspects: agricultural and environmental history of the regions, developmental history and process of the ALUS programs within the study areas, and final products and deliverables of the programs (Table 2). Visits to the locations of the ALUS programs allowed for documentation of qualitative data and trends such as site conditions, community impacts, and other important factors of the type that are not normally conveyed through the technical 
Table 2. Landscape architecture case-study methodology from Francis (1999), as modified for agricultural comparisons.

\begin{tabular}{|c|c|}
\hline Information & Description/Questions \\
\hline \multirow{4}{*}{ Program Base Info } & Where is the program? \\
\hline & Who are the managers? \\
\hline & How much land and what type of ALUS projects are enrolled? \\
\hline & Number of producers enrolled? \\
\hline \multirow{4}{*}{ Agriculture Base Info } & Soil types and erodibility. \\
\hline & What types of agriculture are in the area and the environmental issues? \\
\hline & $\begin{array}{l}\text { What are the natural ecosystems of the region and how has agriculture } \\
\text { changed it? }\end{array}$ \\
\hline & Are there any other environmental impacts? \\
\hline \multirow{5}{*}{ Program Development } & How was the program developed and why? \\
\hline & Who were the main drivers for the program? \\
\hline & What professionals were used to develop the program? \\
\hline & How were farmers involved? \\
\hline & How was the project modified over the course of development? \\
\hline \multirow{3}{*}{ Goals } & What were the program goals? \\
\hline & How were they defined and by who? \\
\hline & Were they changed during the project and how? \\
\hline \multirow{4}{*}{ Financial } & What was the initial project budget? \\
\hline & What was the final budget? \\
\hline & Was there a difference and why? \\
\hline & What was the source of financial support? \\
\hline \multirow{2}{*}{ Process } & How was the program developed? \\
\hline & How were ES selected? \\
\hline \multirow{2}{*}{ Lessons Learned } & What lessons were learned in the course of the project? \\
\hline & How did they affect the project? \\
\hline \multirow[t]{2}{*}{ Outside Critiques } & Input from industry/government that has been documented. \\
\hline & What problems is the program trying to address? \\
\hline \multirow{3}{*}{$\begin{array}{c}\text { Definition of the } \\
\text { Responses to Problem }\end{array}$} & Where it/they resolved? \\
\hline & How/why not? \\
\hline & Were other problems solved? \\
\hline \multirow{3}{*}{ Ancillary Use } & Are the ALUS enrolled lands used in any way? \\
\hline & Recreational use? \\
\hline & Conservation use? \\
\hline \multirow{2}{*}{ Unique Constraints } & Were there any unique constraints? \\
\hline & How were they addressed? \\
\hline \multirow{2}{*}{ Community } & How is the community served by the project? \\
\hline & Social impact, meaning? \\
\hline
\end{tabular}


literature (Prokopy, 2011). Proponents for ALUS argue that these qualitative aspects, such as community empowerment, are the key reasons underlying the success of the ALUS approach (Delta Waterfowl, 2013). However, these have often been overlooked in third-party program assessments which often examine only the economics and conservation merits of the ALUS concept. Furthermore, due to inaccuracies in the passive recollection of natural conditions by respondents in traditional surveys (Owen et al., 2009), we employed in situ "go-along" conversations with practitioners (Carpiano, 2009; Evans \& Jones, 2011), aided by using landscape features as prompts (Riley, 2010). Such an approach provides an accurate assessment of farmer attitudes regarding ES (Greenland-Smith, 2014). The data collected were examined using a directed content analysis (Hsieh \& Shannon, 2005), building on the intuitive methodology of grounded theory (Charmaz, 2006), with coding as per the standard procedure in social science agricultural research (Roesch-McNally et al., 2018), which in the present case, was based the categories of the case-study methodology adapted from Francis (1999).

The present paper highlights a qualitative appraisal of the recurring themes and emerging lessons from a cross-system examination of the ALUS programs. These themes are based upon the comparisons and contrasts of the findings from the programs, with the lessons organized under the following four overarching categories: location, administration and funding, delivery, and development. The Results section (based on information obtained from site visits, interviews, and background documents) goes through the most salient features of the various ALUS programs, after which the Discussion section provides evaluation of the overall strategies.

\section{Results (Program Elements Findings)}

\subsection{Program Location}

Across Canada, the regions that are home to ALUS programs (Figure 1) boast very different natural ecosystems, including prairies (great northern plains or eastern patches), mixed grasslands, aspen parkland, and various forest types (boreal, Carolinian, eastern deciduous, and Acadian), wetlands, and open badlands (France \& Campbell, 2015). Our examination found that the establishment of an ALUS program was irrespective of the type of environment other than the dominating presence of agriculture and general concerns about the environmental repercussions. ALUS is applicable to any area experiencing environmental problems associated with modern agricultural production, which can be compensated for by retiring marginal land or implementing BMPs to enhance ES. Areas with less intensive agriculture, such as Norfolk County and Grey/Bruce Counties in Ontario, still retain a substantial amount of their existing natural capital. Alternatively, areas with more intensive agriculture, such as Western Canada and all of PEI, have reduced natural capital that is often accompanied by more severe environmental disturbances such as fish kills due to pesticide runoff 
in PEI and eutrophication of prairie lakes due to inadequate riparian buffer strips in the West. However, many program administrators felt that it is doubtful whether an ALUS program, which is intended to preserve and promote natural capital in working agricultural landscapes, could be used as a solution where either (a) large-scale and long-term land retirement and restoration would be needed, as for example the creation of wildlife sanctuaries, or (b) in cases where restoration is legally required of ecosystem functions that have been very severely degraded.

Interviewed participants uniformly endorsed the capping principle of ALUS, which maintains agricultural landscapes by setting a limit on the amount of land individual farmers can enroll. This was particularly well displayed in the very successful program in Norfolk County, Ontario, as well as the expired program in the RMB, Manitoba. Elsewhere, developing and pilot phase programs have placed less emphasis on capping, as ALUS demonstration projects in these locations are unlikely to produce regional economic impacts given that only a small area of encompassed land is removed from production. Notably, PEI has not implemented capping as its province-wide ALUS program is addressing widespread and serious water quality and erosion issues caused by widespread intensive potato agriculture.

In most of the regions with ALUS programs, agriculture was not the sole economic driver. In Western Canada, the County of Vermillion River (CVR), and Parkland County, Alberta, are heavily involved in the oil and gas industry, and in PEI and Ontario, the ALUS program locations are also important for tourism. Interestingly, participants, both administrators and farmers, thought that ALUS is able to benefit both these sectors, for example, as a potential offset for oil and gas production, or in terms of protecting and promoting cultural ES (i.e. environmental resources such as recreation areas and aesthetics) as a potential to draw tourists to multifunctional rural areas.

\subsection{Program Administration and Funding}

All of the ALUS programs are characterized by a diverse portfolio of stakeholders and supporters comprised of farmers, eNGOs, and various branches of government (France \& Campbell, 2015). This diversity offers the strength of enabling multiple goals that target the environment, agriculture, and the surrounding community. There was common agreement that in addition to helping to create a more multifunctional program, diversity in the administration also brings additional expertise and in-kind support, as well as networking to the financial partners.

During the initial ALUS pilot program in the RMB, Manitoba, non-farmer stakeholders (such as eNGOs) consulted with agricultural producers to develop the program and prove the concept. By tailoring the program to suit farmers and providing targeted funding, this first ALUS program focused on finding a solution to the conservation needs of the non-farmer stakeholders, specifically the 
funding bodies which included foreign natural resource agencies, at the same time as addressing the wishes of resident farmers.

PEI utilized a different approach for their provincially funded program. Although administered exclusively by the provincial government, during the development of the program external stakeholders from industry, communities, and eNGOs were relied upon for guidance in generating a sustainable program that would have broad acceptance. Currently, the government administration meets annually with these stakeholders to review the program and to suggest modifications if needed.

The Partnership Advisory Committee model, since being formalized in Norfolk County, Ontario in 2007, has become the central structure in all current ALUS programs across the country, with the exception of PEI's unique top-down program. With representation on the PAC from municipal and provincial governments, eNGOs, and predominantly farmers, this model keeps program development and administration at the grassroots level, and was endorsed by all as setting the new standard. Norfolk County's PAC further engages producers by appointing five of its ten farmer members as liaisons. These liaisons were believed by participants to assist the ALUS coordinator by providing initial and continuing communication with interested farmers, thereby helping to establish trust. Many proponents have pointed to the strength of this model as part of the success of ALUS for engaging farmers in the program, not only in Norfolk County, but also elsewhere across the country.

Significantly, our examination found that the deemed effectiveness of an ALUS program was not influenced by the particular administration structure. However, because many farmers are often distrustful of government and eNGOs, the involvement of farmers in the ALUS administration process is opined across the board as being de rigueur to the acceptance of the program by the agricultural community.

With the exception of province-wide program operating in PEI, present-day ALUS programs were not primarily supported by governmental funding. As a result, many of those interviewed expressed concerns about the longevity of these programs due to their reliance upon grants from various funding agencies in order to administer ALUS payments. Despite this implicit uncertainty, ALUS in Norfolk County, Ontario has been extended beyond its initial pilot phase to become a full-fledged program in the absence of significant government funding. Furthermore, it is worth noting that as a result of the continued support and interest from funding partners, no ALUS program has been terminated since that of the original pilot project in the RMB, Manitoba, and even there, we were told that discussions are presently underway to resurrect that widely regarded program.

The initial ALUS pilot in Manitoba was supported by the provincial government, federal crown corporations, and, interestingly, American fish and wildlife agencies. This highlights that there is a place for government funding in ALUS, 
though most programs are not primarily reliant upon that form of financial support. However, despite not being funded directly by government, our examination found that many programs have been successful in obtaining support. In Alberta, for example, the designation of the CVR as a wetland restoration agency has enabled that county's ALUS program to be able to access provincial money specifically targeted for wetland restoration. Although this funding cannot be used for annuities, it did help with the initial costs of designing and implementing the BMPs.

PEI's ALUS program is fortunate with its budget of one million dollars allotted annually by the provincial government. Although we were informed that this generous budget has allowed PEI to have some of the highest levels of ALUS participation and annuity payments across Canada, concerns were nevertheless shared that the program's long-term survival is still ultimately dependent upon the political will of the current governing party. In comparison, some participants from across the country noted, in a glass half-full manner, that other ALUS programs which are only partially funded by or supported with in-kind support from provincial or municipal governments, would not be subjected to unmanageable and abrupt changes set in place by a new political landscape.

\subsection{Program Delivery}

Providing a positive market value for the production of ES is the fundamental function of all the ALUS programs. Our examination found that the payment levels vary greatly, depending on the agricultural practices and location. For example, annuities paid on a per-hectare basis for the initial project in the RMB were $\$ 38, \$ 19$ and $\$ 13$ for no agricultural use, no haying, and no grazing, respectively. Annuity rates for enrolling retired marginal land in the CVR, Alberta are as low as $\$ 13 /$ ha, whereas payments in Norfolk County, Ontario are as high as $\$ 375 /$ ha. We found that the highly variable payment rates seen across the country reflect differences in opportunity costs and local land values. Despite the low payment amounts offered in some cases, such as in Manitoba's RMB, where the average per annum compensation totaled just $\$ 1800$, most farmers across Canada we interviewed considered the payment they received as fair compensation for their efforts (though, of course, not surprisingly, some would like to be paid more for ALUS-enrolled land). It is worth noting in general, and in the case of PEI in particular, that program administrators told us that lower ALUS payments, while less appealing to individual farmers, are of overall benefit to agriculture as they prevent market distortion by artificially increasing land values. Interviewed administrators went out of their way to note that such distortion occurred in the American CRP during the 1980s when the payments, which were larger than land rental fees, caused the value of farmland to increase because of a capitalization of this potential revenue.

Compliance monitoring is undertaken in all ALUS programs to ensure that farmers are carrying out the agreed projects to deliver ES on enrolled lands. 
However, our examination found that the monitoring procedure is certainly not universal and varies in its implementation among the various programs. For example, the CVR's ALUS program conducts annual compliance monitoring prior to making annuity payments. Within this program there have been cases where farmers have been unable to complete the intended project due to vagaries of inclement weather. In these cases, administrators informed us that the CVR ALUS honoured their payments. PEI's ALUS program randomly audits ten percent of its ALUS enrollments each year. The province's program has adopted a non-compliance protocol which stops subsequent payment to delinquent participants, something which, however, administrators told us they had not yet had to enforce. This is because the few issues of non-compliance have been caused by miscommunication, often between farmers and their employees, and not due to a deliberate abuse of the program by the managing farmer her/himself. And in the RMB, Manitoba, former program administrators informed us that compliance monitoring had been inconsistent due to agents of the Manitoba Crop Insurance Corporation, the agency responsible for the monitoring, having varying interpretations about the specifics entailed in ALUS enrollment. For example, some monitoring agents had expected to see total non-use and completely undisturbed land being set aside, and therefore subsequently disqualified farmers based on the presence of all-terrain vehicle tracks and even footprints in pothole wetlands. This disgruntled many farmers, those whom we interviewed telling us that they had in consequence subsequently voiced their discontent at public gatherings and meetings.

As seen in the previous examples, compliance monitoring does not need to be consistent among the various programs. Differences are bound to exist due to the idiosyncrasies of location and the resources of the program dedicated to undertaking the monitoring. However, there was a common opinion of all interviewed participants that it is essential to have uniform compliance monitoring within any individual ALUS program in order to ensure that farmers, technicians, and monitoring officials all have the same understanding of the expectations.

Our examination found that the ALUS concept has been received with a mixture of supportive recognition for its novel nature, as well as some criticism for the manner of its implementation. Indeed, based on the collective opinions shared by participants, each individual program has had its own set of successes and shortcomings. In general, participation in ALUS has been embraced by different types of farmers, ranging from those owning or operating large business-oriented farms to those whom are small-scale hobby farmers. By eliminating monetary penalties ("sticks") and instead offering modest incentives ("carrots") for environmental work, financially motivated farmers are willing to participate in ALUS. For the environmentally-minded farmers we interviewed, ALUS is viewed as a tool to help implement environmental projects faster than would otherwise be possible.

One recurring concern held by participating PAC eNGO members across the 
country is the belief that farmers will only maintain ALUS projects on marginal land provided that payments are continued. Although this concern should not be overlooked, promising indicators have come from Norfolk County, Ontario, with the majority of surveyed farmers telling us they would keep ALUS projects intact should payments cease. In fact, it is critical to note that many of the farmers participating in ALUS programs across the country we spoke with describe feeling more reward from the societal recognition of their role as environmental stewards than from the financial compensation which, while important, is often considered to be of secondary consideration.

Reactions from governments about ALUS have been mixed, according to the opinions of program administrators. Whereas the provincial government of PEI has fully endorsed ALUS, other provincial governments have been less supportive. Some program administrators shared a common regret that their provincial governments, although interested in ALUS, often do not fully understand its potential or use. The first ALUS in the RMB, Manitoba, for example, was heavily criticized by government and eNGOs for focusing on maintaining existing natural capital, with only slight consequent increases devoted to building new capital in terms of creating wetlands and other wildlife habitat.

Another interesting result from our examination was that numerous ALUS proponents commenting on the Canadian federal government's stance, opined that development of the program on a national scale would not be financially feasible. Program managers concurred that ALUS at a national scale would be untenable due to centralized control (though there are some whom disagree and are actively investigating the possibility of just such a nation-wide program). Instead, by maintaining control at smaller regional scales, these interviewees believed that the ensuing programs can be more focused and efficient at delivering targeted and meaningful environmental solutions. Across the board, again and again, we were told that the perception of the program as a grassroots initiative is widely acknowledged by all participants as being one of its strengths in building farmer engagement.

\subsection{Program Development}

All of the ALUS programs were developed similarly: in general, ES that were needed were identified, and the program was based on the capability of farmers to provide those ES. Although the goals of each program were often similar, our examination found that the motivation and the process to select these goals often differed among the programs. Slight differences existed in program development with respect to how each integrated with existing environmental programs and how ALUS was launched in each respective location.

Integration into existing environmental programs represents a core principle of the ALUS concept to complement rather than to compete. For example, multiple programs have been integrated with provincial EFPs, requiring the participation in these programs in order to qualify for receiving ALUS payments. This 
allows the farmer to access cost-share funding, through the EFP, for installation of on-farm BMPs, thereby leaving the ALUS funding to be used solely for annuity payments. One notable exception is PEI's ALUS program which does not mandate farmers to participate in its EFP. However, PEI does integrate ALUS into existing cost-share funding specifically targeted for the construction of erosion control structures and riparian zone enhancement. Our examination found that ALUS programs elsewhere have partnered with local organizations and programs to facilitate targeted on-farm projects, such as that in Grey/Bruce County in Ontario, for example, with the Sydenham Sportsman Association, a local group interested in preserving cold-water fisheries (France \& Campbell, 2015). There was a general agreement among stakeholders that ALUS programs are therefore very effective at complementing and enhancing existing conservation programs and directives. By offering prolonged payments for the production of ES, administrators told us that ALUS makes many cost-share programs more attractive and feasible for farmers.

Use of preliminary demonstration projects of the ALUS concept has been a critical component of the unveiling of each program to the agricultural community for seven of the nine case-studies examined. Following an initial development phase, where the PAC identifies the goals and deliverables of the program, ALUS is first implemented though a pilot phase. Usually lasting about three years, administrators believed that the pilot phase generates support for the program by demonstrating to farmers how ALUS can work on their farms and to financial supporters that it is a worthy investment. Following this pilot phase and any necessary fine-tuning in ALUS's delivery, the program becomes fully established and expands to involve more farmers and increased land enrollment.

Only two case-studies did not have an ALUS pilot demonstration: the RMB in Manitoba, and PEI's province-wide program. The Manitoban program was itself a pilot to test the effectiveness and suitability of the overall concept for conservation in agriculture. Originally intended to be the base for a program to be launched nationally, there was never a serious attempt to ensure its long-term viability. We were told that presently work is underway to re-launch ALUS in the RMB, Manitoba, using the now-established procedure of piloting before evolving into an established program. And although PEI's ALUS was not formally trialed before being implemented into a provincial policy, government administrators informed us that ES projects were undertaken in several watersheds to set the groundwork for the program in order to assess farmer involvement in delivering ES, as well as the degree of support from the community. The findings at the conclusion of the two-year period were positive, interviewed farmers telling us that they participated and altered their practices accordingly, and that watershed residents were found to be willing to pay for the expense of producing ES.

There was a widely held opinion that highlighting accrued benefits through a pilot phase and ongoing development is critical to introducing ALUS to farmers 
and other residents in the target areas. By building support and reworking the program to suit the environmental and agricultural goals of the program, the long-term viability was believed by administrators to be more secure. However, as shown in the PEI case-study, it is possible to bypass the pilot phase of an ALUS if another program of similar scope has been previously undertaken and well received.

Across all of the examined ALUS programs, we found that the dual goals of environmental protection/restoration and farmer empowerment were recurring themes. In more established programs, such as those in the CVR, Alberta, Norfolk County, Ontario, and PEI, goals are targeted to address specific environmental and social problems, such as riparian zone enhancement for erosion protection or the establishment of native prairie. For programs in their infancy, such as Grey/Bruce and other counties in Ontario, and Parkland County, Alberta, goals were less specific, focusing on environmental benefits such as general water quality issues, and encouraging farmers to be proactive to prevent the regulation of agricultural activities by outside influences. This difference based on the developmental stage of the programs is likely a consequence of a combination of increased farmer awareness of specific environmental issues, and increased stakeholder interest in using ALUS as a tool for their own conservation goals. Uniquely, PEI's ALUS program is specifically used as a means to complement existing environmental regulations, increase their effectiveness, and to reward compliance.

Whereas ALUS projects are often similar among different programs, our examination found that patterns in their justification appear to be dependent upon population density and the intensity of agriculture in each region. Water quality protection through preserving wetlands, establishing riparian buffer zones, constructing livestock exclusion fencing, and providing off-stream livestock watering were regarded by participants as higher priorities in areas with higher population densities and more intensive agriculture. These areas included Grey/Bruce County, Ontario, the province of PEI, Parkland County, Alberta, and the Rural Municipalities of Francis, Lajord, Indian Head and South Qu'Appelle in Saskatchewan. In more rural and less densely populated areas, such as the RMB, Manitoba, and the CVR, Alberta, participants placed more emphasis on retiring marginal land and on increasing the area of wildlife habitat. Interestingly, Norfolk County, Ontario, did not prioritize water quality despite the relatively high population density. This may be due to the region's history in tobacco agriculture which required a small working land base. Therefore, despite the presence of over 1,300 farms in this southern Ontario county, most are small, so the impact on waterways has not been as great as in areas of high intensity agriculture such as that occurring in PEI and the Western Prairie provinces.

\subsection{Importance of Themes on ALUS Program Development}

A simple categorization weighting was ascribed based on the frequency and 
emphasis of mention from the interviewed individuals. The relative importance of each of the themes deduced from the cross-system examination played different roles in shaping the goals, project design, and implementation of each individual ALUS program (Table 3). Concepts that were considered of major importance to individual programs were often a principle reason for the initiation of ALUS or heavily considered during program development. Considerations of minor importance were built upon, but were not critical in the administration, goals, or implementation of the particular ALUS program. While some of the deduced themes are not yet applicable in the developing or recently established programs, only three were deemed not applicable in two programs. The first ALUS program in RMB, Manitoba did not place an emphasis on the administration structure or the implementation method to build support and guarantee

Table 3. Comparison of the importance of the deducted cross-system themes in the development and delivery of studied ALUS programs in Canada. 1-Major importance, 2-Minor importance, N/A-Not applicable (for defunct program of RMB and province-wide program in PEI) and N/Y-Not yet applicable (for other ongoing programs). Importance discrimination designations explained in the text.

\begin{tabular}{|c|c|c|c|c|c|c|c|}
\hline \multirow{2}{*}{ Cross-System Theme } & \multicolumn{7}{|c|}{ ALUS Program } \\
\hline & $\mathrm{RMB}^{1}$ & $\mathrm{PC}^{2}$ & $\mathrm{SK}^{3}$ & $\mathrm{~GB}^{4}$ & $\mathrm{CVR}^{5}$ & $\mathrm{NC}^{6}$ & PEI $^{7}$ \\
\hline Program Location & - & - & - & - & - & - & - \\
\hline Natural Ecosystems & 1 & 2 & 1 & 2 & 1 & 1 & 2 \\
\hline Economy & 1 & 2 & 1 & 2 & 1 & 1 & 2 \\
\hline $\begin{array}{c}\text { Environmental Impact of } \\
\text { Agriculture }\end{array}$ & 1 & 1 & 1 & 1 & 1 & 2 & 1 \\
\hline Administration Structure & - & - & - & - & - & - & - \\
\hline Composition & 2 & 1 & 1 & 1 & 1 & 1 & 1 \\
\hline Structure & N/A & $\mathrm{N} / \mathrm{Y}$ & 1 & 1 & 2 & 1 & 1 \\
\hline Funding & 1 & 2 & $\mathrm{~N} / \mathrm{Y}$ & $\mathrm{N} / \mathrm{Y}$ & 2 & 1 & 1 \\
\hline Program Delivery & - & - & - & - & - & - & - \\
\hline Payments & 1 & 2 & 2 & 2 & 2 & 1 & 1 \\
\hline $\begin{array}{l}\text { Compliance } \\
\text { Monitoring }\end{array}$ & 1 & $\mathrm{~N} / \mathrm{Y}$ & $\mathrm{N} / \mathrm{Y}$ & $\mathrm{N} / \mathrm{Y}$ & 1 & 1 & 1 \\
\hline Acceptance and Criticisms & 1 & 1 & 1 & $\mathrm{~N} / \mathrm{Y}$ & 2 & 1 & 2 \\
\hline Program Development & - & - & - & - & - & - & - \\
\hline $\begin{array}{l}\text { Integration with Existing } \\
\text { Environmental Programs }\end{array}$ & 1 & $\mathrm{~N} / \mathrm{Y}$ & $\mathrm{N} / \mathrm{Y}$ & 1 & 2 & 1 & N/A \\
\hline Implementation Strategy & N/A & 1 & 1 & 1 & 1 & 1 & 2 \\
\hline Goals & 1 & 1 & 1 & 1 & 1 & 1 & 1 \\
\hline Prioritization of Goals & 1 & 2 & 2 & 2 & 2 & 1 & 1 \\
\hline
\end{tabular}

${ }^{1}$ Rural Municipality of Blanshard, Manitoba. ${ }^{2}$ Parkland County, Alberta. ${ }^{3}$ Rural Municipalities of Francis, Lajord, Indian Head and South Qu'Appelle, Saskatchewan. ${ }^{4}$ Grey and Bruce Counties, Ontario. ${ }^{5}$ County of Vermillion River, Alberta. ${ }^{6}$ Norfolk County, Ontario. ${ }^{7}$ Prince Edward Island. 
longevity. PEI's provincial ALUS program made very little attempt to integrate with existing environmental programs as it was meant to complement specific regulations.

\section{Discussion}

\subsection{Environmental Impact}

As a conservation minded, land management strategy, ALUS appears to be very adaptable. Its grassroots approach has meant that the various programs entail both land-sparing and land-sharing conservation strategies. Being attuned to local conservation goals, each program is molded by regional agriculture, natural ecosystems, and cultural values, with no common one-size fits all, cookie-cutter model. In Western Canada, ALUS is more comparable to a land-sparing tool (i.e. separating agriculture and conservation), being based on retiring extensive areas of high slope and other marginal land. In Ontario, ALUS is exhibited more as a land-sharing program (i.e. integrating conservation into agriculture), based on retiring small parcels of marginal land, enhancing streams and wetlands, and incorporating ES such as bird and pollinator habitat admix agriculture. The program of PEI has hints of both, in terms of retiring high-slope land while also improving the function and biodiversity of riparian zones.

Although ALUS is heralded by its champions as a successful environmental program, its outcomes and benefits have not been consistently assessed in any of the individual programs. Upon visiting ALUS projects across the country, it appeared that the sites were in better environmental condition compared to similar sites located nearby that had not been altered through implementation of BMPs. However, whereas the improvements can be seen and expressed anecdotally, we determined that there is a serious shortage of quantitative and even qualitative data on accrued environmental benefits beyond the simple metric of the areal size of projects. There has not been a thorough evaluation of the extent of ES that are supposed to be provided or the value of the ensuing natural capital in the enrolled ALUS projects. Specifically, some of the criticisms about the initial ALUS pilot in the RMB, Manitoba, for example, may have been due to a lack of outreach to "prove" or even to explain the benefits, in addition to a lack of emphasis on re-establishing new protected lands. Later ALUS programs have learned from this and have consequently focused on both expanding natural capital in addition to protecting existing land. However, from our investigation we believe that attempts at protecting existing natural capital in these projects could be boosted by increased data collection to help build a better case for their inherent natural value. Unfortunately, with the notable exceptions of Irvine's (2013) survey of pollinators in Norfolk County, Ontario, and Mann et al.'s (2014) post hoc application of the European Union's Agri-environmental Footprint Index (AFI) (Mauchline et al., 2007) for the RMB, Manitoba, this is something that has been ignored across the board. This is a missed opportunity to increase the scientific credibility of ALUS programs and thus their salience to 
still-sceptical governmental officials. Given ALUS's stated objectives to integrate with existing environmental initiatives, we strongly believe that the programs should engage with the various government agencies that have the resources in place to collect better environmental data, and to conduct monitoring, thereby allowing ALUS administrators to focus on issues of farmer engagement and project administration.

During our research, the term ES was loosely used to include wildlife habitat, erosion control, and water quality. Although there can be little doubt that marginal land taken out of agriculture has positive environmental benefits for water quality and wildlife habitat, there was an immediate inference of multi-functionalism in providing numerous ES. This problem is not unique to ALUS and is symptomatic of a recurring attempt to simplify ecosystem functions by many different programs that use market-based instruments of applying economic value to ES (Burgin, 2008; Walker et al., 2009; Robert \& Stenger, 2013). Whereas ES such as native pollinators or enhancement of game species may be quick and easy to assess, other ES could take far longer to establish and gauge.

The voluntary nature of the ALUS programs, although promoting the production of site-specific ES such as erosion control and wildlife habitat, may limit the desired environmental goals that can be attainable on a regional scale. Farmers who have no desire to participate in ALUS, or who consciously farm in a manner that is environmentally damaging, can hinder the programs. In such cases, ALUS would have little regional impact, necessitating reliance on traditional legal regulations that would become the primary means in which to stop environmental degradation. In such cases, we consider that PEI, which uses its ALUS program as a complement to regulation, could serve as a model for situations where voluntary stewardship is deemed or determined to be insufficient to ensure that regional environmental conditions are maintained at, or are restored to, an acceptable level. That said, such governmental oversight may run counter to the noted independent-mindedness that characterizes many farmers. In such cases, a form of an "alter-PES", operated by environmentally-conscious farmers, might develop in the shadow of the formal ALUS program (Kolinjivadi et al., 2019).

\subsection{Social Impact}

The most dramatic finding from our survey of the various programs across Canada is that ALUS as a concept has had far more benefit in terms of socially empowering farmers than it has in terms of enhancing environmental conditions. By including farmers in many stages of program development as well as administrative processes, barriers of uncertainty and mistrust that often characterize interactions between resource managers such as farmers, and the lay public and especially government officials, have been circumvented while creating realistic environmental goals for all stakeholders to endorse. Program managers have observed this in many programs such as, for example, the CRV, Alberta, 
which at first had attracted only a handful of skeptical farmers. Within a year, however, a similar meeting promoting ALUS in the county attracted more than a hundred farmers and ranchers, all acutely interested in ALUS. We feel that this social empowerment is the true strength of the ALUS program which, once established, can set the foundation for more sound environmental work to be undertaken. Other, subsequently conducted and site-specific investigations have reached similar conclusions (MacLean, 2014; Holland, 2015).

From our conversations with participants and administrators, it became apparent that farmers felt that the main benefit for ALUS programs was the societal recognition for their role as environmental stewards. It is this social capital that is the main driving force behind ALUS participation, with the financial incentives, which can be very modest, being viewed as a secondary benefit.

The level of incentives must be carefully calibrated for reasons other than avoiding market distortion. There is, for instance, a real risk of financial incentives "crowding out" more intrinsic motivations to farm sustainably (Greiner \& Gregg, 2011; Vollan, 2008), causing worse conditions when the incentives expire. It can also degrade conditions in places where incentive funding is not yet available, as farmers see the potential for future payments to do something they might have otherwise done anyway. Also, another potentially deleterious repercussion is that some farmers might be tempted to intensify production in order to compensate for land taken out of production through being given over to ALUS (Kolinjivadi et al., 2019). On the other hand, with respect to producing positive financial benefits, given the increasing difficulty of farming some marginal land in the face of climate-related extreme weather, ALUS may make common sense in simply providing a better land-use strategy to apply in toto for net collective gain; i.e. a classic example of hedging one's bets (France \& Campbell, 2015).

\subsection{Financial Sustainability}

During our research there was an ongoing concern expressed by many of those interviewed about the long-term financial stability of the ALUS programs given that, with the exception of PEI, they all lack major governmental support. Whereas this concern is well-grounded, the continued funding of the Norfolk program beyond the initial pilot phase, through the support of the Garfield Weston Foundation and other funding partners, illustrates an optimistic model. Likewise, similar success with the ALUS program of the CVR, Alberta, due to being recognized as a wetland restoration agency, suggests another possible model for funding continuance. The key is to be opportunistic and to demonstrate a high degree of entrepreneurship. Notably, these are traits that are de rigueur for any successful eNGO operating in the present-day climate of limited or ephemeral funding, and thus suggests that experienced members of such environmental groups be included in early stages of ALUS project development as an integral part of the assembled PACs. 
PEI's ALUS program, which has had continued financial support from its provincial government, does not have the short-term financial concerns of other ALUS programs. Although it is a provincial policy and relatively stable, it could be subject to a change in political will, whereby the program could quickly lose its funding. However, it is believed that in PEI's case this is very unlikely as the program has been very successful when used in conjunction with existing environmental regulations in the province.

Some ALUS programs are looking at developmental offset-and-trading mechanisms to bring in revenue. The lack of data about the value of the natural capital together with the controversial nature of offset trading may limit this approach. The literature is reasonably clear that credit and banking style restoration may not provide the same ES as those lost in the area being developed (Robert \& Stenger, 2013). However, the strategy does provide opportunity to mitigate and allow economic development while encouraging the production of ES in agricultural landscapes which may already be highly disturbed, such as those in the peri-urban intreface.

The financial efficiency of the ALUS program is something that was only briefly mentioned by administrators, but is something that we believe should be more strongly championed. By engaging farmers, who already own both land-working equipment and hold operation experience, in the physical implementation of the recommended BMPs, the programs do not have to invest significant capital or labour to undertake ALUS projects. There are some exceptions where specialized equipment has had to be purchased, such as a grass-seed harvester in Norfolk County, Ontario, or where wetland restoration has been subcontracted to specialized professionals. But, overall, ALUS seems to be a very cost-effective mechanism through which to get environmental mitigation and restoration in the ground.

\section{Implications for Land-Use Planning and Sustainable Agro-Ecosystem Management}

\subsection{Natural Capital Shortcomings and Recommendations}

The investigated ALUS programs, despite being touted for providing environmental benefits, lack quantifiable data on their ability to increase ES. This is a serious shortcoming that should be explicitly addressed in the establishment of any and all future programs. At best, however, in the case of past and present ALUS projects, environmental improvements can be inferred based on qualitative observations. But there can be no denying that heuristic experience is but a poor substitute for gauging environmental performance, just as is the areal extent of protected or restored land a poor surrogate for ES (France, 2003). It is worth noting that such deficiencies in quantifiable data are common in many attempts to simplify the complex relationships existing between natural capital and the ES they provide (Robert \& Stenger, 2013). The use of a comprehensive evaluation index such as the AFI, applied to the RMB, Manitoba's defunct ALUS 
program (Mann et al., 2014), or the Environmental Benefits Index, used to assess the CRP in the United States (Smith, 2003), is to be encouraged.

\subsection{Social Capital Concerns and Strengths}

Financially, ALUS does face uncertainty, but this is typical of most present-day environmental programs. The continued financial support of ALUS, as well as its ability to use the participant's on-farm equipment and experience, serves to increase its viability, thereby reducing the resources needed to operate the program compared to other environmental programs. This suggests an optimistic future for ALUS's continuation as an economically efficient strategy for agricultural stewardship and environmental improvement. Ongoing investigation into more stable programs, such as EFP, seems necessary. Presently, Nova Scotia, for example, is investigating whether to implement an ALUS program as part of its EFP. In France and Campbell (2015) we list ten key elements to consider and ten mistakes to avoid to increase the likelihood of success with planning, administering, and implementing an ALUS program.

There are two distinct models that have been used for the administration of ALUS, each having its own particular advantages and disadvantages. PEI's top-down model has many strengths including financial security, resources for compliance monitoring, and access to government resources. However, despite using a grassroots approach to develop the program, there are still members of the province's farming community that feel more consultation with them is needed, in addition to greater outreach in order to encourage other, presently reticent and possibly recalcitrant individuals who are not currently implementing ALUS on their farms (Lantz et al., 2012). Feelings of a lack of real autonomy are obvious shortcomings of such a top-down administrative structure, established with only minimal input from farmers (Kolinjivadi et al., 2019). Elsewhere across Canada, however, the bottom-up approach that has been adopted by all other past and present ALUS programs, most notably through the PAC framework, has been extremely successful in engaging farmers (Mackenzie, 2008; Rosenberg, 2010; MacLean, 2014; Holland, 2015), and as we found in our cross-system examination, has garnered their widespread endorsement. The idea of an administrative format closely reliant upon a PAC comprised of knowledgeable stakeholders has been suggested as a valuable, grassroots-based, governance structure that could be adopted to improve restoration efforts in the marine coastal zone, a region whose knowledge base and experience level in this regard are lacking compared to those in the terrestrial landscape (France, 2016). ALUS therefore can offer lessons of use for environmental restorationists and land-use managers beyond the bailiwick of agricultural production.

The social impact of the ALUS program has been its greatest success. By engaging farmers for the initial and ongoing development, and/or contributing to administration, ALUS has managed to overcome the endemic apprehensions and occasional mistrust that many farmers have about environmental programs 
and government oversight (Lawrence et al., 2004). This supports research by Knowler and Bradshaw (2007) indicating increased social capital as being one of the most important influences on why farmers undertake environmental work. In short, farmers want to do the right thing in terms of finding a balance between production and conservation (McGuire et al., 2013). In this regard, ALUS can pave the way for farmers, who appear to be driven more by social capital benefits in terms of increased societal reputation as good stewards, than they are by accruing increased financial incentives, to work with eNGOs and governments to attain mutually agreeable environmental outcomes. Finally, ALUS appears to be representative of a growing body of research suggesting that it is the process of participating in environmental restoration that is ultimately just as or even more significant than any environmental products ensuing therefrom (France, 2008; Egan et al., 2011).

\section{Acknowledgements}

This research was supported by grants from Agriculture and Agri-Food Canada, Delta Waterfowl, the Nova Scotia Federation of Agriculture, and the NSAC Class of 56. Discussions with Jim Fisher, Jonathan Scarf, Shawn Hill, Lindsey Bennet, Keith Reid, Niall Kuyek, Gabriel Clark, and Joan Gabrielson were instrumental to the various case studies investigated. Nancy MacLean, Peter Havard and $\mathrm{Al}$ Hansen are thanked for reviewing an earlier draft of this research. All procedures performed in studies involving human participants were in accordance with the ethical standards of the institutional and/or national research committee and with the 1964 Helsinki declaration and its later amendments or comparable ethical standards.

\section{Conflicts of Interest}

The authors declare no conflicts of interest regarding the publication of this paper.

\section{References}

ALUS (2011). ALUS: Beginning; and How ALUS Works. http://alus.ca

Bailey, R. O., \& Reid, D. J. (2004). ALUS: The Farmer's Conservation Plan. Norfolk Federation of Agriculture. ALUS Canada, Toronto, Ontario.

Burgin, S. (2008). BioBanking: An Environmental Scientist's View of the Role of Biodiversity Banking Offsets in Conservation. Biodiversity and Conservation, 17, 807-816. https://doi.org/10.1007/s10531-008-9319-2

Campbell, J. B. (2014). A Case-Study Analysis of the Alternative Land Use Services Program (ALUS). M.Sc. Thesis, Nova Scotia: Dalhousie University.

Carpiano, R. M. (2009). Come Take a Walk with Me: The "Go-Along" Interview as a Novel Method for Studying the Implications of Place for Health and Well-Being. Health and Place, 15, 263-272. https://doi.org/10.1016/j.healthplace.2008.05.003

Charmaz, K. (2006). Constructing Grounded Theory. London: Sage. https://doi.org/10.1002/9781405165518.wbeosg070 
Delta Waterfowl (2013). Adopt a Pothole; and Wetlands Get a Boost in Alberta. http://www.deltawaterfowl.org

Egan, D., Hjerpe, E. E., \& Abrams, J. (2011). Human Dimensions of Ecological Restoration: Integrating Science, Nature, and Culture. Washington DC: Island Press. https://doi.org/10.5822/978-1-61091-039-2

Evans, J., \& Jones, P. (2011). The Walking Interview: Methodology, Mobility and Place. Applied Geography, 31, 849-858. https://doi.org/10.1016/j.apgeog.2010.09.005

Fischer, J., Brosi, B., Daily, G. C., Ehrlich, P. R., Goldman, R., Goldstein, J., Lindenmayer, D. B., Manning, A. D., Mooney, H. A., Pejchar, L., Ranganathan, J., \& Tallis, H. (2008). Should Agricultural Policies Encourage Land Sparing or Wildlife-Friendly Farming? Frontiers in Ecology and Environment, 6, 380-385. https://doi.org/10.1890/070019

France, R. L. (2003). Wetland Design: Principles and Practices for Landscape Architects and Land-Use Planners. New York: W.W. Norton.

France, R. L. (2008). Healing Natures, Repairing Relationships: New Perspectives on Restoring Ecological Spaces and Consciousness. Winnipeg: Green Frigate Books.

France, R. L. (2016). From Land to Sea: Governance-Management Insights from Terrestrial Restoration Research Useful for Developing and Expanding Social-Ecological Marine Restoration. Ocean and Coastal Management, 133, 64-71.

https://doi.org/10.1016/j.ocecoaman.2016.08.022

France, R. L., \& Campbell, J. S. (2015). Payment for Agro-Ecosystem Services: Developmental Case-History Descriptions of Canada's Grassroots “ALUS” Programs. Research Journal of Agriculture and Environmental Management, 4, 405-431.

Francis, M. (1999). A Case Study Method for Landscape Architecture. Brussels: Landscape Architecture Federation. https://www.lafoundation.org/sites/default/files/2019-01/casestudymethod.pdf

Grau, R., Kuemmerle, T., \& Macchi, L. (2013). Beyond "Land Sparing versus Land Sharing": Environmental Heterogeneity, Globalization and the Balance Between Agricultural Production and Nature Conservation. Current Opinions Environmental Sustainability, 5, 477-483. https://doi.org/10.1016/j.cosust.2013.06.001

Greenland-Smith, S. (2014). Farmer Perceptions of Wetland Ecosystem Goods and Services. M.Sc. Thesis, Halifax: Dalhousie University.

Greiner, R., \& Gregg, D. (2011). Farmers' Intrinsic Motivations, Barriers to the Adoption of Conservation Practices and Effectiveness of Policy Instruments: Empirical Evidence from Northern Australia. Land Use Policy, 28, 257-265. https://doi.org/10.1016/j.landusepol.2010.06.006

Holland, K. L. (2015). Transitioning to a New Approach for Sustainability: The Case of Manitoba's ALUS Project. Ph.D. Thesis, Edmonton: Univ. Alberta.

Hsieh, H. F., \& Shannon, S. E. (2005). Three Approaches to Qualitative Content Analysis. Quality Health Research, 15, 1277-1288. https://doi.org/10.1177/1049732305276687

Irvine, C. (2013). Community Composition Change of Pollinating Insects on Farms Enrolled in Alternative Land Use Services Pilot Project in Norfolk County, Ontario. https://alus.ca/wp-content/uploads/2016/08/PollinatorStudy-Irvine.pdf

Johnston, L. (2012). An Assessment of Prince Edward Island's Alternative Land Use Services (ALUS) Program, 2008-2011. M.Sc. Thesis, Fredericton: University of New Brunswick.

Keystone Agricultural Producers (KAP) (2004). A Proposal for the Development of an Alternate Land Use Services Pilot Project in the Rural Municipality of Blanshard. http://www.kap.mb.ca/alus/alus_mar05.pdf 
Knowler, P., \& Bradshaw, B. (2007). Farmers' Adoption of Conservation Agriculture: A Review and Synthesis of Recent Research. Food Policy, 32, 25-48. https://doi.org/10.1016/j.foodpol.2006.01.003

Kolinjivadi, V., Mendez, A. Z., \& Dupras, J. (2019). Putting Nature “to Work" through Payments for Ecosystem Services (PES): Tensions between Autonomy, Voluntary Action and the Political Economy of Agri-Environmental Practice. Land Use Policy, 81, 324-336. https://doi.org/10.1016/j.landusepol.2018.11.012

Kvale, S., \& Brinkmann, S. (2009). Interviews: Learning the Craft of Qualitative Research Interviewing. Thousand Oaks, CA: SAGE Publications Inc.

Lantz, V., Johnston, L., \& Anderson, T. (2012). A Survey of Farmer Perspectives on the PEI ALUS Program. Fredericton: Faculty of Forestry and Environmental Management, University of New Brunswick.

Lawrence, G., Richards, C. A., \& Cheshire, L. (2004). The Environmental Enigma: Why Do Producers Professing Stewardship Continue to Practice Poor Natural Resource Management? Journal of Environmental Policy, 6, 251-270. https://doi.org/10.1080/1523908042000344069

Mackenzie, B. F. (2008). Supporting Environmental Stewardship and Livelihood Benefits in Ontario's Greenbelt: Assessing the Potential Contribution of the Alternative Land Use Services Program. M.Sc. Thesis, Waterloo: Univ. Waterloo.

MacLean, M. K. (2014). We Have a Responsibility: Alternative Land Use Services, Farmers and Environmental Stewardship. M.Sc. Thesis. Guelph: Univ. Guelph.

Mann, J., Grant, C., \& Kulshreshtha, S. (2014). Economics of a Pricing Mechanism to Compensate Rural Land Owners for Preserving Wetlands. Canadian Water Resources Journal, 39, 462-471. https://doi.org/10.1080/07011784.2014.965037

Mauchline, A. L., Park, J. R., Finn, J. A., \& Mortimer, S. R. (2007). The Agri-Environmental Footprint Index. Aspects of Applied Biology, 81, 263-266.

McGuire, J., Wright Morton, L., \& Cast, A. D. (2013). Reconstructing the Good Farmer Identity: Shifts in Farmer Identities and Farm Management Practices to Improve Water Quality. Agriculture and Human Values, 30, 57-69. https://doi.org/10.1007/s10460-012-9381-y

Ouelett, F. (2018). La Participation des Agriculteurs aux Démarches Volontaires en Agro-environnement: Le Cas du Programme Alternative Land Use Service (ALUS) en Ontario. M.A. Thesis, Laval: Université Laval.

Owen, R. J., Duinker, P. N., \& Beckley, T. M. (2009). Capturing Old Growth Values for Use in Forest Decision-Making. Environmental Management, 43, 237-248. https://doi.org/10.1007/s00267-008-9133-3

Prokopy, L. S. (2011). Agricultural Human Dimensions Research: The Role of Qualitative Research Methods. Journal of Soil and Water Conservation, 66, 9-12. https://doi.org/10.2489/jswc.66.1.9A

Riley, M. (2010). Emplacing the Research Encounter: Exploring Farm Life Histories. Qualitative Inquiry, 2, 34-45. https://doi.org/10.1177/1077800410374029

Robert, N., \& Stenger, A. (2013). Can Payments Solve the Problem of Undersupply of Ecosystem Services? Forestry Policy Economics, 35, 83-91. https://doi.org/10.1016/j.forpol.2013.06.012

Robinson, G. M. (2006). Canada's Environmental Farm Plans: Transatlantic Perspectives on Agri-Environmental Schemes. Geographical Journal, 172, 206-218. https://doi.org/10.1111/j.1475-4959.2006.00207.x

Roesch-McNally, G., Gordon, J., \& Tyndall, J. C. (2018). Soil and Social-Ecological Feed- 
back: Examining the "Ethic" of Soil Stewardship among Corn Belt Farmers. Rural Sociology, 83, 145-173. https://doi.org/10.1111/ruso.12167

Rosenberg, J. (2010). An Analysis of the Critical Success Factors for Participation in Agricultural-Environmental Programs: A Case Study. M.Sc. Thesis, Guelph: Univ. Guelph.

Smith, M. (2003). Agricultural Resources and Environmental Indicators: Land Retirement. In Agricultural Resource and Environmental Indicators 2003 (pp. 15, 23-35). United States Department of Agriculture and Economic Resource Service.

https://www.ers.usda.gov/webdocs/publications/41964/30300_landretirement.pdf? v=0

Vollan, B. (2008). Socio-Ecological Explanations for Crowding-Out Effects from Field Experiments in Southern Africa. Ecological Economics, 67, 560-573. https://doi.org/10.1016/j.ecolecon.2008.01.015

Walker, S., Brower, A. L., Theo, R. T., \& Lee, W. G. (2009). Why Bartering Biodiversity Fails. Conservation Letters, 2, 149-157. https://doi.org/10.1111/j.1755-263X.2009.00061.x

Zhang, Y., \& Wildemuth, B. M. (2009). Unstructured Interviews: Applications of Social Research Methods to Questions in Information and Library Science. Exeter: Libraries Unlimited. 